Revista Bioética

\title{
EDITORIAL
}

\section{Bioética: ponte para um futuro pós-pandemia}

Tatiana Bragança de Azevedo Della Giustina ${ }^{1}$, José Hiran da Silva Gallo ${ }^{1}$, Rui Nunes ${ }^{2}$

1. Conselho Federal de Medicina, Brasília/DF, Brasil. 2. Universidade do Porto, Porto, Portugal.

$\mathrm{O}$ ano de 2020 tem sido difícil para todos. Desde o primeiro bimestre, o mundo se viu assolado por uma nova enfermidade surgida na China, causada pelo vírus Sars-CoV-2. A origem do patógeno não é completamente conhecida, mas sabe-se que a doença é altamente contagiosa, tendo rapidamente se espalhado pelos continentes, a ponto de ser declarada pandemia pela Organização Mundial da Saúde em 11 de março de $2020^{1}$.

A alta taxa de transmissão e morbidade da covid-19 a torna capaz de sobrecarregar os sistemas de saúde, requerendo a adoção de medidas como distanciamento social, uso de máscaras, lavagem constante das mãos e desinfecção com álcool em gel. Além disso, quando essas medidas não são suficientes, ações governamentais mais severas são necessárias, como quarentena obrigatória, lockdown, multas e toques de recolher, o que impacta seriamente a economia de diversos países.

De acordo com Schmidt e Medeiros ${ }^{2}$, o vertiginoso aumento populacional nas grandes cidades e a atual facilidade de deslocamento pelo mundo favorecem a disseminação de doenças contagiosas e o estabelecimento de emergências de saúde pública. A dificuldade em conter o avanço da doença e a constante busca por estratégias para atender à demanda do sistema de saúde implicam a ideia de uma verdadeira "saúde global", envolvendo esforços internacionais coordenados.

A resposta da comunidade científica à pandemia foi intensa, mas ainda não resolutiva. As evidências epidemiológicas para a covid-19 estão sendo estabelecidas, do ponto de vista do tratamento, do diagnóstico e mesmo da prevenção, e a doença e suas diferentes manifestações estão sendo pesquisadas em todo o mundo. Mesmo sem uma base definitiva de evidências, entidades médicas criam protocolos para atendimento amparados em tratamentos disponíveis, sempre respeitando o princípio bioético da autonomia do médico e do paciente. Além disso, diversas vacinas estão sendo desenvolvidas e testadas de forma emergencial, sempre visando o bem comum, mas por vezes ocultando conflitos de interesse de grandes grupos farmacêuticos.

Os dilemas éticos envolvendo o gerenciamento de recursos e as demandas sanitárias estão cada vez mais presentes, incutindo a necessidade e a oportunidade de refletir sobre a atual situação e suas implicações bioéticas ${ }^{3}$. Nesse cenário, a interface entre direitos humanos e o interesse público despertado pela crise pandêmica pôs à prova a solidez dos princípios bioéticos das sociedades contemporâneas.

Um desses dilemas remete à vacina contra a covid-19. Uma vez desenvolvida, como devem agir os governantes? Devem torná-la obrigatória, seguindo viés utilitarista, dada a possibilidade de contágio e adoecimento severo, levando a hospitalização e cuidados intensivos? Ou devem respeitar a individualidade e a liberdade de quem não quer se vacinar ${ }^{4}$ ?

No Brasil, foi decretado em março de 2020 estado de calamidade pública ${ }^{5}$, possibilitando a liberação de orçamento extra independentemente da Lei de Responsabilidade Fiscal ${ }^{6}$, e em maio foi declarada situação de Emergência em Saúde Pública de Importância Nacional ${ }^{7}$. Isso permitiu que políticas públicas fossem reorientadas para o combate à pandemia, viabilizando o emprego urgente de medidas de prevenção, controle e contenção de riscos, danos e agravos à saúde pública. Estados de calamidade e emergência em saúde pública são estabelecidos em

\section{Bioética}

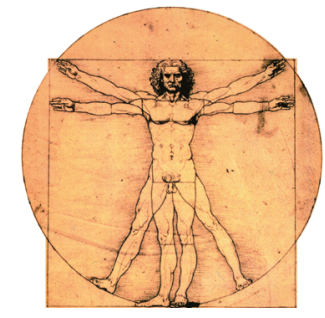


situações epidemiológicas que apresentam risco de disseminação por todo o país e/ ou que extrapolam a capacidade de resposta da direção estadual do Sistema Único de Saúde?

Passados alguns meses do início da pandemia, ainda não houve tempo suficiente para desenvolver medicamentos e vacinas que cumpram o rigoroso protocolo habitual. A necessidade premente dessas soluções deve fazer repensar a ética dos estudos com seres humanos, em especial os ensaios clínicos de novos medicamentos, assim como o papel dos comitês de ética em pesquisa.

Embora vários medicamentos, como remdesivir, hidroxicloroquina, dexametasona, ivermectina, nitazoxanida e plasma convalescente, estejam sendo utilizados em pesquisas, a covid-19, em suas diversas manifestações, ainda não foi totalmente compreendida ${ }^{8}$. Lamentavelmente, foram observados conflitos de interesse em pesquisas clínicas por todo o mundo, e muitas visões políticas têm também influenciado iniciativas científicas para possíveis tratamentos e vacinas. Na perspectiva bioética, isso implica que mecanismos internacionais de controle e regulação da ciência precisam ser fortalecidos, de modo que o conceito de "medicina baseada em evidências" não seja apenas uma pálida miragem do que poderia ser.

Este ano de 2020, já quase no fim, trouxe mudanças expressivas para a medicina, a saúde, a bioética e as relações humanas. Também a Revista Bioética este ano passou por mudanças, enriquecendo a equipe editorial com o professor doutor Rui Nunes como editor científico honorário, a professora doutora Natália Teles como editora-assistente e o professor doutor José Hiran da Silva Gallo como editor científico no Brasil. Tem ainda buscado novas plataformas internacionais de indexação, com o objetivo de elevar o fator de impacto do periódico.

Nestes tempos de pandemia, a bioética tem sido lembrada pelas possibilidades de refletir sobre a crise sanitária, os dilemas éticos e a forma de conduzir os casos clínicos. Com isso, esta última edição de 2020 apresenta diversos temas do interesse de todos, inclusive sobre a covid-19, mas para além dela. Boa leitura!

Os editores

\section{Referências}

1. OMS afirma que covid-19 é agora caracterizada como pandemia. Opas Brasil [Internet]. Banco de Notícias; 11 mar 2020 [acesso 12 nov 2020]. Disponível: https://bit.ly/3oe7oY5

2. Schmidt AKI, Medeiros RVZ. Discussões bioéticas em tempos de pandemia. In: Farias RN, Mascarenhas IL, organizadores. Covid-19: saúde, judicialização e pandemia. Curitiba: Juruá; 2020. p. 197-213.

3. Correa LC. Utilitarismo e moralidade: considerações sobre o indivíduo e o Estado. Rev Bras Ciênc Soc [Internet]. 2012 [acesso 14 nov 2020];27(79):173-86. DOI: 10.1590/S0102-69092012000200011

4. Savulescu J. Good reasons to vaccinate: mandatory or payment for risk? J Med Ethics [Internet]. 2020 [acesso 14 nov 2020]. DOI: 10.1136/medethics-2020-106821

5. Brasil. Decreto Legislativo $n=6$, de 2020. Reconhece, para os fins do art. 65 da Lei Complementar no 101 , de 4 de maio de 2000, a ocorrência do estado de calamidade pública, nos termos da solicitação do presidente da República encaminhada por meio da Mensagem no 93, de 18 de março de 2020. Diário Oficial da União [Internet]. Brasília, no 55-C, edição extra, p. 1, 20 mar 2020 [acesso 14 nov 2020]. Disponível: https://bit.ly/36rDdXm

6. Brasil. Lei Complementar $n=101$, de 4 de maio de 2000. Estabelece normas de finanças públicas voltadas para a responsabilidade na gestão fiscal e dá outras providências. Diário Oficial da União [Internet]. Brasília, p. 1, 5 maio 2000 [acesso 14 nov 2020]. Disponível: https://bit.ly/3muS1dd

7. Brasil. Decreto no 7.616, de 17 de novembro de 2011. Dispõe sobre a declaração de Emergência em Saúde Pública de Importância Nacional (Espin) e institui a Força Nacional do Sistema Único de Saúde (FN-SUS). Diário Oficial da União [Internet]. Brasília, p. 14, 18 nov 2011 [acesso 10 dez 2020]. Seção 1. Disponível: https://bit.ly/2JvVr11

8. Folha informativa covid-19: Escritório da Opas e da OMS no Brasil. Opas [Internet]. 2020 [acesso 12 nov 2020]. Disponível: https://bit.ly/3odaj3b

Tatiana Bragança de Azevedo Della Giustina - Doutora - tatiana.giustina@portalmedico.org.br

(iD) 0000-0001-5905-4722

José Hiran da Silva Gallo - Doutor - gallo@portalmedico.org.br

(iD) 0000-0002-1848-7270

Rui Nunes - Doutor - ruinunes@med.up.pt

(D) 0000-0002-1377-9899 